\title{
A System for Assessment of Students Performance at College of Computers and Information Technology, Taif University
}

\author{
Mahmoud Rokaya \\ College of Computers and Information Technology, Taif university \\ Taif, Saudi Arabia \\ Faculty of Science, Tanta University \\ Tanta, Egypt
}

\begin{abstract}
It is very important to find an automated method to assess and evaluate the students' performance in each curriculum. In this paper, the general framework of a system, fully automated, to collect and assess the student's outcomes is presented. The main goal is to automate the data collection and analysis process. Also, the system is designed to represent a repository of the assessment data, programs information and all manuals related to the assessment process details and the system itself. The system was able to reduce the manual work to the be minimal and enabled the instructors and different committee to access the assessment and evaluation data for the current and previous years.
\end{abstract}

\section{General Terms}

Information System, Applications of Computer Science in Modeling, Data and Information Systems.

\section{Keywords}

Assessment System. Evaluation, Student Outcome, Course learning Outcome, Assessment Matrix.

\section{INTRODUCTION}

Student assessment and evaluation are very important to determine to what extent the student acquired knowledge, skills and competences in a specific course or program. Planning for improvement in teaching and learning can get benefits from the assessment process. The results of assessment can be shared with relevant stakeholders. [1, 2]. The current work explains the evaluation of the assessment data used in course and program assessment at College of Computers and Information Technology, Taif University. the performance metrics have been derived and respective formulas to calculate the attainment of course learning outcomes and student outcomes both at the course and program levels. Some studies tried to explore the attainment of student outcomes as a case study for a specific course [3..6] or a case study for a whole program [7..10]

Some papers demonstrated the assessment method based on linking course assessments to learning objectives [11, 12]

important implications for instructional improvement. In this paper, a system for collecting, sharing and assessment is introduced. The system helps the curriculum committee to enter the predefined Students Outcomes (SOs). In each course, the curriculum committee defines the mapping between the Course Learning Outcomes (CLOs) and the SOs of the program and also define the mapping between the CLOs and the course topics. Each instructor can develop his own assessment strategy by defining a set of specific assessments that covers all the course CLOs. The system enables the instructors to define each assessment, map the individual's questions inside each assessment to one or more CLO. Also, the instructor can enter the indirect assessment data (Course Survey). Once the instructor defines his assessment strategy, he (she) can enter the marks of each assessment. The system gives alarm to the mandatory inputs that the instructor must enter to be able to generate the assessment results of his section(s). The system summarizes the attainment levels of each CLO and each SO in a tabled and graphs presentation, this called Course Assessment of Faculty (CAF). The system provides an automated form that enables each instructor to enter his comments regarding the levels of CLOs and SOs attainment as well as difficulties and suggestions. When all instructors complete their assessments entering, the course coordinator can generate the combined course report that summarizes the attainment levels of SOs and CLOs in a given course. The system again enables the coordinators through an automated form to enter their comments and suggestions to improve the course. When all instructors and coordinators complete entering their data correctly, the system can generate the Program Level Report which gives the average attainment levels of all SOs and the attainment level of SO in each course. This helps the curriculum committee to define which SOs do not achieved the attainment target and in which course and in which section(s). This tracking method saves the committee time and guide it to distill the relevant reports and concentrate to develop an improving plan(s) based on instructors and coordinators comments for the course(s) that causes the low level under the target of a given SO.

The remaining parts of this papers are organized as follows. Section 2 gives the definitions of the main concepts that are used through the paper. Section 3 presents a mathematical notations and model structure as well as the formulas used to calculate the attainment levels. Section 4 presents the details of the experiments to use and evaluate the system performance and efficiency. Section 5 presents the discussions and future work as well as the main results.

\section{DEFINITIONS AND CONCEPTS}

In this section, the definitions of all terms that are used through the paper are presented.

Assessment: "assessment is a term used to mean methods or tools that teaching staff members use to evaluate, measure, and document the academic readiness, learning progress, skill acquisition, or educational needs of students" [16]. Student 
outcomes are assessed using both direct and indirect assessment tools. Indirect assessments are acquired from the course CLOs exit survey and graduate exit survey.

Evaluation: Evaluation is a more general concept than the assessment. It expresses the value meaning of the numerical value. It includes both tangible and intangible qualities. [13]

Student Outcome (SO): Student Learning outcomes describe essential learning that learners have gained. It can demonstrate at the end of a program.. [14].

Example: "using of current techniques, skills, and tools necessary for computing practice"

Course Learning Outcome (CLO): "Course learning outcomes define what the learner will know and can do by the end of a course" [15]

Example: Describe, in general basic file structure and indexing technique.

Attainment Level: Attainment level of a students, in a topic, CLO, or SO, is the percent of students who got marks greater than attainment target. In our system, the percent of total marks that the student got to the total marks of the related questions is taken and compared to check whether this percent is greater than the attainment levels.

Attainment Target: Attainment target is the percent that the system uses to calculate the attainment level. An example will be presented in section 3 .

Instructor: Instructor is a member of teaching staff who teach the theory or practical part for one or more sections of students in a given course

Course Assessment of Faculty (CAF): Course Assessment of Faculty is a file generated by the system after entering the required grades of the students by the instructors for a given section. CAF contains statistics that summarize grade report, survey results and attainment statistics of the CLOs and SOs.

Faculty Assessment Report (FAR): Based on the CAF, faculty Assessment report is a form that is filled by the instructor to enter his comments regarding the students results, attainment levels of CLOs and SOs. The form enables the instructor to enter the problems that faced him during the teaching process and his suggestions to improve the course

Course Coordinator: Course coordinator is a teaching staff who is responsible to follow up the instructor, coordinate between them and review and approve the assessment tasks of each instructor. Also, the coordinator is responsible to generate the course report and to write the coordinator report

Course Report: Course report is an automated file that can be generated by the system and summarizes all statistics of all sections in a given course

Coordinator Report: Based on course report: Course report is a form filled by the course coordinator to collect all common comments, suggestions and issues raised by all instructors to define improvements that raised to the curriculum committee to.

Program Level Report (PLR): Program Level Report is an automated file that is generated by the system. This file consists of rows, representing the courses, and columns, representing the SOs. Each cell in this file represents the attainment level. The last row represents the average attainment of each SO
Program Report: Program report is a form filled by the curriculum committee. Based on the PLR, the curriculum committee can decide which SOs failed to achieve the attainment target. Also by tracing back the values of attainment levels in each section, the curriculum committee can define the sections that causes this failure in each course related to the failed SO. Based on the FAR and the coordinator reports, the curriculum committee can distil the actions that should be taken to improve the SOs attainment levels in all courses. These actions are called the program improvement plan (PIP).

\section{THE MODEL}

This section presents the mathematical notations and the formulas that are used to calculate the attainment level of SOs and CLOs. Also, the general structure of the system will be explored.

\subsection{Mathematical representation of attainment:}

Suppose that $M_{q, a, s}$ be the grades achieved by student $s$ in question $q$ of assessment $a$ (mid-exam, final-exam, classwork, project, quiz, ...). Note that $a$ can have the values, $a=$ $1,2, \ldots, A, q$ can take the values $q_{a}=1,2, \ldots, Q_{a}$, and $s$ can have the values $s=1,2, \ldots, S . A, Q_{a}, S$ represent the total number of assessments, questions in assessment $a$, and the student's number, respectively. If a given course is related to $C$ number of CLOs then $c^{\text {th }}$ CLO can be expressed as $C L O_{c}$, $n=1,2, \ldots, C$.

The three-dimensional matrix $M$ can be rewritten as a twodimension matrix $\breve{M}$ as

$$
M=\left[\begin{array}{llll}
M_{1}^{T} & \overline{M_{2}^{T}} & \ldots & M_{I}^{T}
\end{array}\right]
$$

Where $M_{i}^{T}$ presents the transpose matrix of $a^{\text {th }}$ assessment matrix $M_{A \times M}$. Matrix $\breve{M}$ has the dimension $M \times L$, where $L=\sum_{i=1}^{I} Q_{a}$

CLO to SO mapping matrix is expressed by

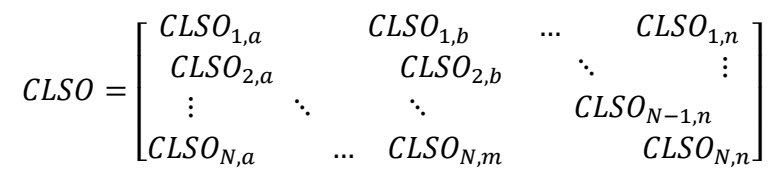

The matrix element $C L S O_{n a}$ is has only two values. If the CLO $\mathrm{n}$ contributes in measuring SO $a$, then $C L S O_{n a}=1$, otherwise $C L S O_{n a}=0$. [13]

In the Same manner, the CLO to question mapping is expressed by:

$$
C L O Q=\left[\begin{array}{ccccc}
C L O Q_{1,1} & C L O Q_{1,2} & & \ldots & C L O Q_{1, L} \\
C L O Q_{2,1} & C L O Q_{2,2} & & \ddots & \vdots \\
\vdots & \ddots & \ddots & & C L O Q_{N-1, L} \\
C L O Q_{N, a} & \ldots & C L O Q_{N, L-1} & C L O Q_{N, L}
\end{array}\right]
$$

In $C L O Q$ Matrix, the values of the entries is either 1 or zero. $C L O Q_{n, l}=1$ if question $l$ is used to measure $C L O_{n}$. [14]

For each CLO, the attainment value (attain_CLO ${ }_{n}$ )is given by

$$
\text { attain_CLO } n=\frac{\sum_{i=1}^{I} \frac{1}{M_{i}} \sum_{j=1}^{J_{i}} Q P S_{i, j} \times C L O Q_{n, i, j} \times Q_{i, j}^{\text {tot }}}{\sum_{i=1}^{I} \sum_{j=1}^{J_{i}} Q_{i, j}^{t o t} \times C L O Q_{n, i, j}}
$$

Where, $Q P S_{i, j}$ is the number of students who got marks greater than the attainment target $P T_{i, j}$ in question $i$ in assessment $j . P T_{i, j}$ can be varied from, however, in our 
experiments, the values that were used of $P T_{i, j}$, are $60 \%$ for all assessment tasks in all courses and $80 \%$ for the project's courses. $Q_{i, j}^{\text {tot }}$ is the total number of questions and assessments related to $C L O_{n}$. [15]

For each $\mathrm{SO}$, the attainment value (attainment $\mathrm{SO}_{n}$ ) is given by:

$$
\operatorname{attain} S_{-} O_{n}=\frac{\sum_{i \in C^{n}} \text { attain_CLO }{ }_{i w_{i}}}{\sum_{i \in C^{n}} w_{i}}
$$

Where, $w_{i}$ is the weight of $C L O_{i}$ counted in calculating the $S O_{n}$ attainment. $w_{i}$ can be varied based on the level of the course that $C L O_{i}$ belongs. Since all course that participated in the assessment experiment are from higher levels and all of them are core courses, a fixed weight $w_{i}=1$ is used for all CLOs.

\subsection{System Model.}

Fig.1 is a flowchart that represent the main component of the system. The system was designed to help the teaching staff in all assessment activities. The repository of the system contains the syllabus, teaching materials, exams and samples of previous semesters. The system enables the instructors to define their own assessments as well as defining the mapping between each question in each assessment and the course CLOs. After the defining step, each instructor enters his student's marks then the instructor clicks generate CAF button to get his CAF report. The system enables each instructor to fill the FAR form then he can generate the FAR report that contains a summary of assessment results and comments entered by the instructor for each section. At the course level, the coordinator can generate the course report that contains summary of all section results. Based on the course report and the instructors FARs reports the coordinator can generate the coordinator report. At the program level, the representative of the curriculum committee can generate the PLR. PLR enables the curriculum committee to evaluate the attainment of each SO and trace the reports back to define the reasons of failing a given SO to achieve the attainment target. The curriculum committee concludes an action plan based on the SOs evaluation and instructors and coordinators comments and suggestions.

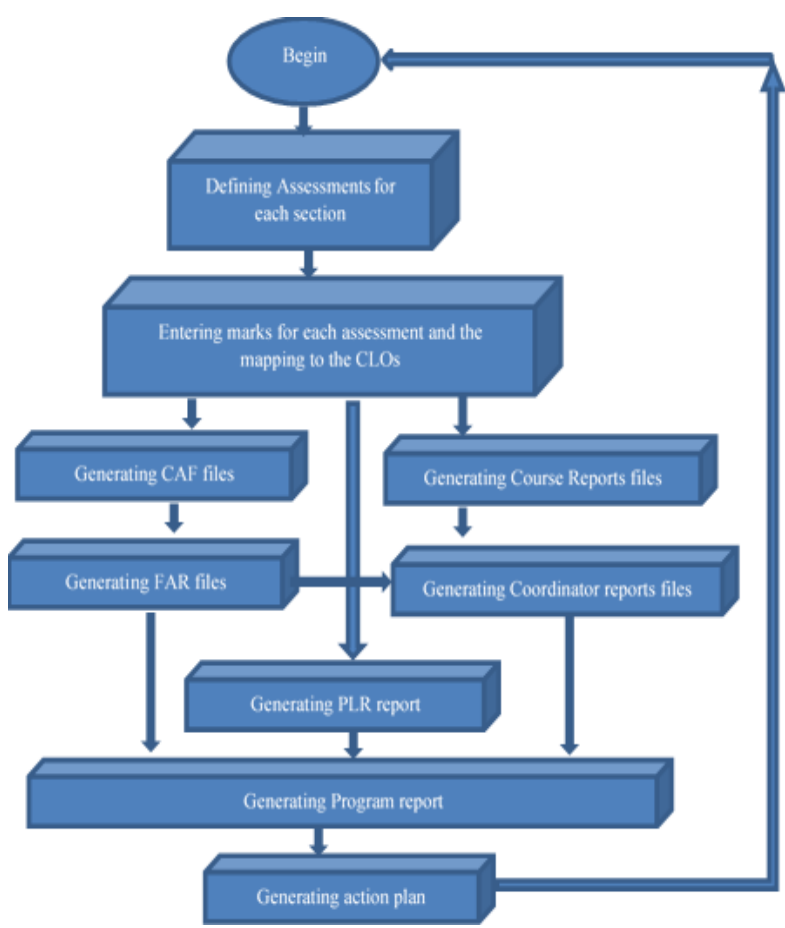

Fig1. Assessment and evaluation flow chart in the assessment system

\section{THE EXPERIMENTS}

The system was written and implemented in python under the supervision of the PAC committee (Performance Assessment Committee) at the college of computers and information technology, Taif University. The system was implemented and used to enter the data of 420 different sections in Taif University, College of Computers and Information Technology, Fall 2019, Information Technology Program. Figure 2. Shows a sample of the dashboard of the system.

The PAC team entered the mapping between each course topic and CLOs as well as the mapping between the CLOs of each course and the corresponding SOs provided by the Information technology curriculum committee.

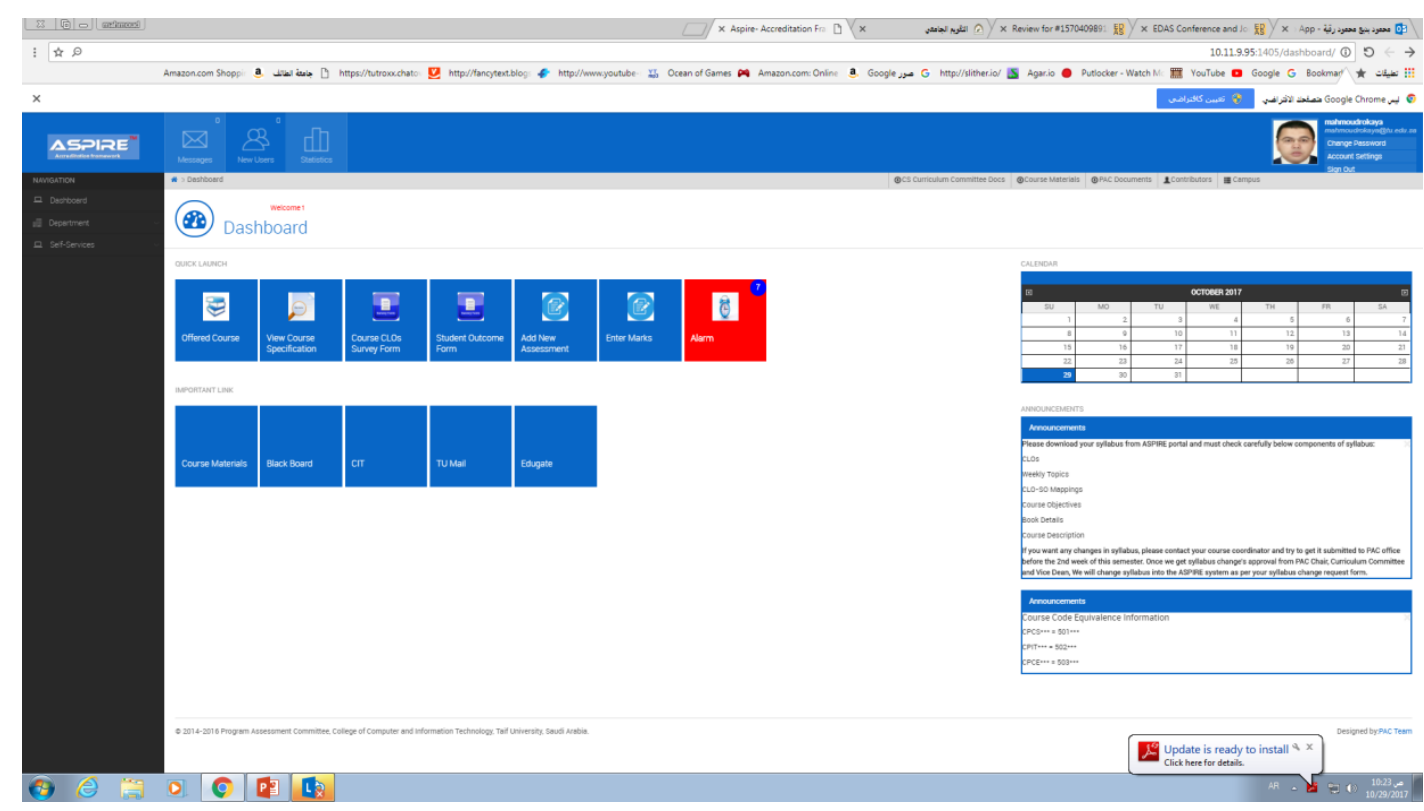

Fig. 2. a view of the system main screen (system dashboard) 
Table 1. List of selected courses

\begin{tabular}{|c|c|}
\hline Domains & Selected Courses \\
\hline \multirow{4}{*}{$\begin{array}{l}\text { Professional } \\
\text { domain }\end{array}$} & 500300-2 Professional Ethics \\
\hline & 502462-3 IT Project Management \\
\hline & 502598-3 Capstone Project (1) \\
\hline & 502599-3 Capstone Project (2) \\
\hline \multirow{4}{*}{$\begin{array}{l}\text { Software } \\
\text { domain }\end{array}$} & 501323-3 Objected-Oriented Programming \\
\hline & 502315-3 Web Systems \\
\hline & 502373-3 Database Management Systems \\
\hline & 502464-3 Software Architecture \\
\hline \multirow{5}{*}{$\begin{array}{l}\text { Systems } \\
\text { domain }\end{array}$} & 502420-3 System Administration \\
\hline & 502459-3 Computer Systems Security \\
\hline & $\begin{array}{c}\text { 502463-3 System Integration and } \\
\text { Architecture }\end{array}$ \\
\hline & 502583-3 Net. Servers and Infrastructure \\
\hline & 502584-3 Advanced Topics in Networks \\
\hline \multirow{3}{*}{$\begin{array}{l}\text { Theory } \\
\text { domain }\end{array}$} & 502321-3 Fund. of OS \\
\hline & 502361-3 System Analysis \& Design \\
\hline & 502482-3 Fund. of Network \\
\hline
\end{tabular}

To test the system, a number of courses were selected by the curriculum committee in the information technology program. Table 1 shows these courses and their distribution over the students' skills domains.

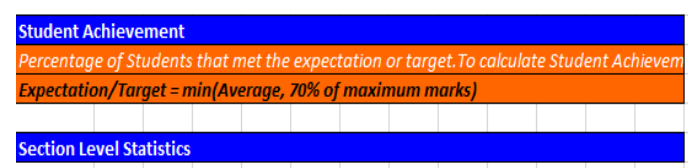

\section{SOs Attainment}

Average of $\%$ CLOS attainment that map to particular SO.
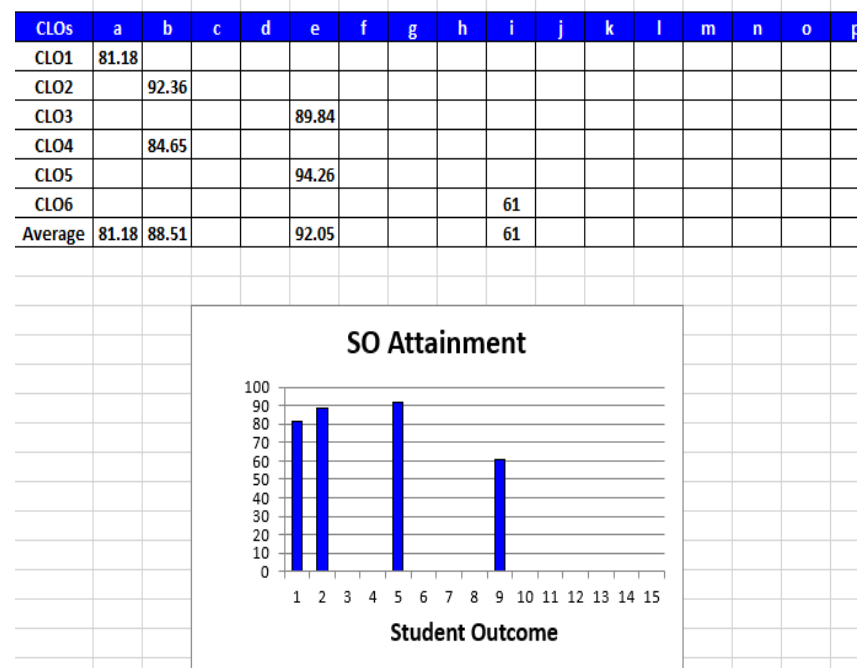

Fig. 4. an example of SOs attainment results in 502373-3 DBMS course for one section
Fig. 3 and Fig. 4 shows examples of the assessments results provided by the system for the CLOs and related SOs at course section level. Fig. 5 and Fig. 6 show the SOs and CLOs attainment levels at the course level.

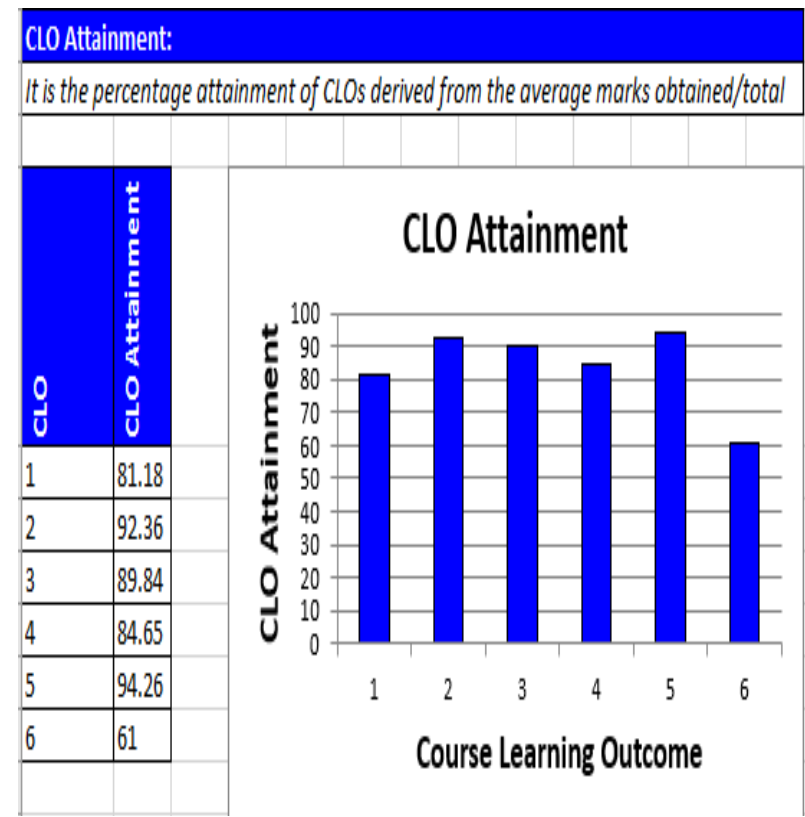

Fig. 4. an example of CLOs attainment results in 502373-3 DBMS course for one section

These results were produced for 502373-3 Database Management Systems course. Fig. 7 shows an example of the summary (PLR report) produced by the system to represent the average of attainment level of each SO as well as the level of attainment for each SO. The system was designed to produce all these results automatically after completing the entry of marks step in each selected course for the assessment purposes.

An example of how the curriculum committee used the PLR report to trace Bach and evaluate one the SOs is shown in Fig. 8.

\section{DISCUSSION AND RESULTS}

The system gave the members of teaching staff and their assistance the chance to enter their comments and suggestions to improve the system. The results ensure that there are positive impact and support to continue in developing the system was . Most comments related to the availability of the system inside the university domain only. Also, some instructors commented on the style of the interface and asked for more flexible easier representation. Some coordinators commented on the inflexible manner of the system in producing the course report, the system gave an error when trying to produce the report if one or more section is not completed. To solve these problems, it is recommended to enable the application from the information technology center at Taif university to be available for the members from outside the university domain. Also, it was recommended to give the coordinator the privilege to enable or disable the course sections if some of these sections were not completed. For the dashboard, some suggestions recommended to provide some training sessions especially for new users beside the available manuals and recorded videos. 

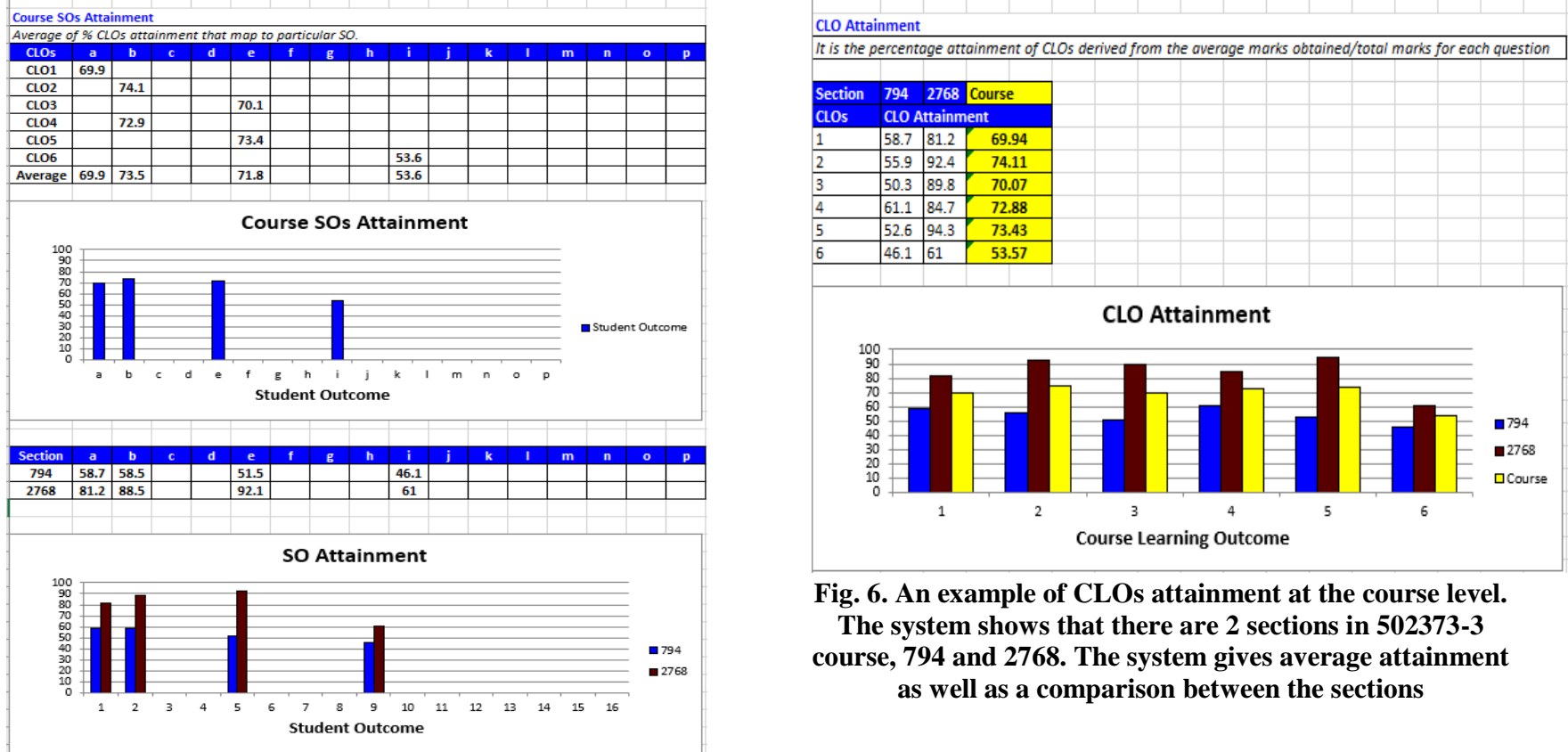

Fig. 6. An example of CLOs attainment at the course level.

The system shows that there are 2 sections in 502373-3

course, 794 and 2768 . The system gives average attainment as well as a comparison between the sections

Fig. 5. An example of SOs attainment at the course level.

The system shows that there are 2 sections in 502373-3

course, 794 and 2768 . The system gives average attainment as well as a comparison between the sections

\begin{tabular}{|c|c|c|c|c|c|c|c|c|c|c|c|c|c|c|c|c|c|}
\hline & \multicolumn{13}{|c|}{ SO Attainment } & \multirow[b]{2}{*}{ I } & \multirow[b]{2}{*}{ m } & \multicolumn{2}{|r|}{ CS ABET } \\
\hline & Code & Course Name & $\mathbf{a}$ & b & c & d & e & $f$ & $\mathbf{g}$ & h & $\mathrm{i}$ & $\mathrm{j}$ & $\mathrm{k}$ & & & $\mathrm{n}$ & Course Code \\
\hline \multirow{4}{*}{ 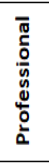 } & $500300-2$ & Professional Ethics & & 74.94 & & & 77.38 & & 76.52 & 79.35 & 74.28 & & & & & & $500300-2$ \\
\hline & $502462-3$ & IT Project Management & & & & & & 75 & & & & & & & & 70 & $502462-3$ \\
\hline & 502598-3 & Capston Project 1 & & & & & & & & & & & & & & & 502598-3 \\
\hline & $502599-3$ & Capston Project 2 & & & 91.82 & 91.43 & 91.69 & & & & & & & & & & $502599-3$ \\
\hline \multirow{4}{*}{ 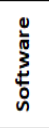 } & 501323-3 & Object Oriented Programming & & & & & & & & & & & & & & & 501323-3 \\
\hline & $502315-3$ & Web Systems & 72.17 & 65.57 & & & & & & & & 50.02 & & 57.79 & & & 502315-3 \\
\hline & 502373-3 & Database Management Systems & 74.59 & 65.86 & & & 55.25 & & & & 42.04 & & & & & & 502373-3 \\
\hline & $502464-3$ & Software Architecture & 70.78 & & 66.81 & & & & & & & & & & & & $502464-3$ \\
\hline \multirow{5}{*}{$\begin{array}{l}\tilde{g}^{n} \\
\stackrel{n}{n} \\
\hat{n}\end{array}$} & $502420-3$ & System Administration & & & & & & & & & & & & & & & $502420-3$ \\
\hline & $502459-3$ & Computer System Security & 81.5 & 81.2 & 81.2 & & 76.39 & & & & & 76.39 & 76.39 & & & & 502459-3 \\
\hline & 502463-3 & System Integration and Architecture & & 74.22 & 61.86 & & & & & & & 52.11 & & & 64.99 & & \\
\hline & $502583-3$ & Net. Servers and Infrastructure & & & & & & & & & & & & & & & 502583-3 \\
\hline & $502584-3$ & Advanced Topics in Networks & & 63.52 & 63.52 & & & & & & 73.24 & & & & 69.65 & & 502584-3 \\
\hline \multirow{4}{*}{  } & $502321-3$ & Fund of OS & 67.35 & 71.52 & 72 & & & & & & & & & & 68.53 & & 502321-3 \\
\hline & $502361-3$ & System Analysis \& Design & & 56.02 & 51.01 & & & & 57.93 & & 61.95 & & & & & & $502361-3$ \\
\hline & $502482-3$ & Fund. Of Network & & & & & & & & & & & & & & & $502482-3$ \\
\hline & & Average & 73.28 & 69.11 & 69.75 & 91.43 & 75.18 & 75 & 67.23 & 79.35 & 62.88 & 59.51 & 76.39 & 57.79 & 67.72 & 70 & \\
\hline
\end{tabular}

Fig. 7. Example of PLR produced by the system
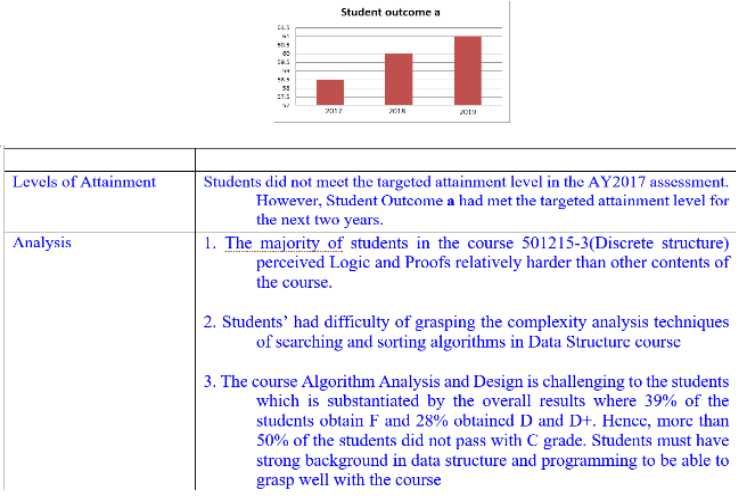

Fig. 8. An example of curriculum committee evaluation of the $\mathrm{SO}$ attainment level in a complete evaluation cycle from 2017, 2018 and 2019

\section{CONCLUSION}

In this work, a system to automate the assessment process for information technology program, college of computers and information technology was explored. The system was able to give the instructors, coordinators and curriculum committee to access and distil the necessary information to complete the evaluation process. The system enables the users to access the syllabus, teaching materials and assessment materials in an organized manner. The future work is to enable the application through the smart phones and to give more flexible interface as recommended by the users.

\section{ACKNOWLEDGMENTS}

The author thanks the assistant staff in the PAC office and all teaching staff in the college of computers and information technology for their highly support and cooperation. 


\section{REFERENCES}

[1] OCDE, 2013, Synergies for Better Learning: an International Perspective on Evaluation and Assessment, ISBN: 9789264190641, https://doi.org/10.1787/978926 4190658-en.

[2] Al-yahya, S. and Abdel-halim, M., 2013, A Successful Experience of ABET Accreditation of an Electrical Engineering Program, IEEE Transactions on Education, Vol. 56, (May 2013), pp. 165-173.

[3] Gökçe, A., 2019, an Assesment on the Course of Professional Ethics Course and its Necessity in Departments of public administration, Journal Of Social Science Institute, Vol. 11(28), pp: 380-387 doi: 10.20875/makusobed. 541245, 2019

[4] Dewa, D., Baso, S., Gusti, P., Ketut, D., Luh, A., Sundayana, M., et. Al., 2017, An Evaluation of Instructional Process of Expert System Course Program by Using Mobile Technology-Based Cse-Ucla Model, IJIM - vol. 11, no. 6, http://www.i-jim.org

[5] Carbonaro, A. and Ravaioli, M., 2017, Peer Assessment to Promote Deep Learning and to Reduce a Gender Gap in the Traditional Introductory Programming Course, Journal of E-Learning and Knowledge Society, Vol. 13, n.3.

[6] Soung-mi, N., 2015, A Study on Application Course Embedded Assessment (CEA) for Program Outcome Assessment in Nursing Education, Journal of The Korea Academia-Industrial Cooperation Society, Vol. 16, no. 5 pp. 3121-3130, 2015, http://dx.doi.org/10.5762/kais. 2015.16.5.3121

[7] Reed, J. and Zhang, H., 2013, A Hierarchical Framework for Mapping and Quantitatively Assessing Program and Learning Outcomes, in Proceedings of the 18th ACM Conference on Innovation and Technology in Computer Science Education, P. 5257, ACM.

[8] Cho S., 2016, A Case Study of Course-Embedded Assessment for Program Outcomes in Computer Science
\& Information Engineering, Journal of Internet Computing And Services(JICS) (FEB 2016): 17(1): 7381, http://dx.doi.org/10.7472/jksii.2016.17.1.73

[9] Almadena, A., and and Heng-yu, K., 2017, Analyzing the Curricula of Doctor of Philosophy in Educational Technology-Related Programs in the United States, Educational Media International, Vol. 54, NO . 2, 112 128, https://doi.org/10.1080/09523987.2017.1364210

[10] Pierrakos, O. and Watson, H., 2013, A Comprehensive ABET-Focused Assessment Plan Designed to Involve all Program Faculty, In Frontiers in Education Conference, 2013 IEEE, p. 17161722, IEEE.

[11] Alhassan, M. and Ashur, S, 2013, Developing Course Assessment Tool to Measure the Degree of Achieving Course Learning Outcomes, Systemics, Cybernetics and Informatics Vol. 11 - No. 6.

[12] Murnane, R., Sharkey, N. and Boudett, K., 2005, Using Student-Assessment Results to Improve Instruction: Lessons from a Workshop, Journal of Education for Students Placed at Risk (JESPAR) Vol. 10 NO. 3, (July 2005), 269-280·, DOI: 10.1207/s1 5327671espr1003_3

[13] Reed, J. and Zhang, H., 2013, A Hierarchical Framework for Mapping and Quantitatively Assessing Program and Learning Outcomes," In Proceedings of the 18th ACM Conference on Innovation and Technology in Computer Science Education, (ACM 2013), p. 5257.

[14] Ezeldin, A., 2013, International Accreditation for Engineering Programs: Mission, Learning Objectives and Outcomes," Procedia - Social And Behavioral Sciences, (Nov. 2013), Vol. 102, Pp. 267-275,

[15] Sriraman,V. and Stapleton, W., 2013 Lessons Learned in First Time Accreditation of Engineering Programmes, Global Journal Of Engineering Education, Vol. 15, no. 2.

[16] https://www.edglossary.org/assessment/ 